\title{
UNDERGRADUATE MEDICAL STUDENTS' PERSPECTIVE TO COMMUNITY _BASED EDUCATION AND SERVICES (COBES) ATTACHMENT IN THE RURAL PRIMARY HEALTH CARE SETTINGS IN NAMIBIA.
}

\author{
Longin R Barongo ${ }^{1}$, Linda N Lukolo ${ }^{2 *}$ \\ *1,2, School of Medicine, Faculty of Health Science, University of Namibia, Windhoek,
}

*Corresponding Author:

E-mail:Inlukolo@unam.na; lindalukolo24@gmail.com*

\begin{abstract}
: -
Objective

To examine the students' perspective on whether Community_Based Education and Services (COBES) practices in the rural settings was in line with school learning objectives, be able to identify deficiencies in the design and in the implementation of COBES program

Methods

A total of 100 students were analyzed, 30 out of 55(55\%) from the year 2013, 35 out of 65 (54\%) from year 2014 and 35 out of $70(51 \%)$ from year 2015. These students were randomly selected from the cohort of students in their respective year of study. In their log books students were required to respond to each of the objectives given, the importance of each objectives in relation to the situation they saw in the rural primary health settings and identify deficiencies in the design and implementation of the program.

Results

All students (100\%), acknowledged improved practical skills including history taking, physical examination and performance of outpatient procedures as outlined in their log-books under supervision. More than 2/3 of the students appreciated how the primary health care facilities were organized in a multidisciplinary way and well-coordinated on day to day basis. Among the many challenges identified include inadequate number of staff members, lack of technical and specialist support. About $50 \%$ of the students were able to associate poverty and type of diseases commonly found in those communities.

Conclusion

All the three cohorts expressed that the rural replacement enhanced their learning and increased skills because they were exposed to a variety of medical problems hardly seen at the teaching hospital .About 2/3 of all students appreciated working in a multidisciplinary team that include all primary health care staff. To many students this rotation was an eye opener to the type of life in the rural settings. Some of those students were born and raised in towns.
\end{abstract}

Key words: Undergraduate students' perception, COBES, Rural Primary Health Care attachment, Namibia

Words Key: concepts of drugs emergent, new substances psychoactive, club drugs, synthesis drugs, intelligent drugs.

\section{(c) $(\$)$}




\section{INTRODUCTION}

The School of Medicine was opened in January 2010 with 55 students. It is located in the capital city of Windhoek which has a population of about 380,000 people and that is where training of medical student is taking place. Therefore medical training is predominately urban- based.

Attachment of medical students to primary health care facilities in rural settings is now an integral and important component of medical education internationally $(1,2)$.

One of the main reasons of COBES is to enable the students to put the theory of primary health care as taught in the classroom settings into practice in the rural settings. So, the aim of this study is to examine the students' perspective on whether COBES in the rural settings was in line with the school's learning objective on Primary health care.

\section{The major learning objective of COBES are:}

- To study the structure, staffing, functions and problems of primary health care delivery system in the rural, peri-urban and urban areas in the country.

- To understand the practical elements of primary health care management including patients flow, medical records keeping, how to keep patients confidential information, appreciate the day to day coordination of primary health care services

- To appreciate working with multidisciplinary team including nurses, health officers, attendants, and how health facility administration deals with village leaders and political figures in that community where the health facility is situated.

- To improve efficiency and practical skills in conducting a direct medical history taking, physical examination and performing outpatient procedures as outlined in their logbooks under guidance of experience primary health care staff.

- To appreciate the challenges involved in providing healthcare to medically underserved and impoverished population

- To appreciate the relationship between disease and poverty in the rural settings

It is hoped that rural placement will make the students appreciate the opportunities and challenges experienced by rural communities of Namibia, as well as the risks health care staff in the primary health care settings face on a daily basis.

There is consensus globally that primary health care needs are higher in rural and remote locations, especially amongst children and pregnant women compared to urban areas (1). While about $50 \%$ of the people live in the towns and cities in Namibia, the remaining half live in remote parts of the country COBES is both a training and service oriented program. COBES is mainly facility based focusing on students training at primary health care setting. The main challenge expected in the country is the production of graduate medical doctors who are willing to work in underserved areas. The earlier these students are introduced to rural health care delivery systems in the country the higher the chances that some students may opt to work in those areas $(1,2)$. The third year medical students have just covered biomedical sciences and primary health care; they are in the transition period before joining clinical years. So the service part they can render in the primary health care settings may include a range of activities from taking body weights, blood pressure, temperature and other activities which are pre-defined by the school before attachment to primary health care facilities.

Apart from addressing the issue of training objectives and what is happening in the field as far as primary health care is concerned, the rotation is meant to expose students to the primary health care in the rural settings. Some of the students were born and raised in towns so rural lifestyle is unknown to them. Graduating doctors may prefer to work in the urban areas especially if they are not aware of what is happening in the rural health care settings. So, early introduction of medical students to the rural community may influence their future choice of working areas. Studies done in other universities among medical students around the world, showed a positive attitude towards rural placement. (1)

There is a shortage of doctors working in rural areas all over the world, especially in lowincome and middle-income countries. The choice to practice medicine in a rural area is influenced by many factors. Motivation of medical students in the early years of their medical training has been found to be one of the key determinant of this choice $(1,2)$.

Studies have shown that students who attend a rural rotation show an appreciation of the opportunity to gain insight into an unfamiliar setting, noting that disease pattern in rural communities is significantly different from those seen among the metropolitan populations

$$
(3,4,5)
$$

One of the factors affecting community health in rural areas is misalignment of population and healthcare work force in Namibia. Approximately 50\% of the population in Namibia live in rural areas, however more than $75 \%$ of healthcare workforce train and pursue employment in cities and big towns in the country. The majority (about 70 to $80 \%$ ) of medical specialists, medical officers, pharmacists and registered nurses serve only about $50 \%$ of the population in Namibia.

A study done at Makerere University in Uganda has shown that training of medical students in COBES has significantly contributed to the solution of the problem of inequality distribution of health care staff in the country. More doctors are currently more willing and able to work in the underserved rural communities $(6,7)$

COBES training program is expected to equip students with competencies that will help them in future when serving rural health communities e.g. leadership skills, ability to work in a team, and capability to interact with communities. It is also expected to give them opportunities to learn and work with other primary health care cadres and interact with community leaders. (11)

Since the start of the COBES program in the year 2013 to date no evaluation of the program to show whether student perspectives accord with school objectives.

This article presents a three year feedback from students on their experience in a remote rural clinical placement in Namibia from 2013 to 2015 
This is a new institution, we still soliciting views from all players including students as a way of providing education that fits the national and international standards. In this study the aim was to examine the undergraduate medical students' perspective on whether community_based education and services (COBES) attachment in the primary health care settings is meeting the outlined objectives and intended outcome as planned by the School of Medicine.

\section{Methods}

\section{Study design}

This was mainly qualitative and semi- structured quantitative research methods. An explorative design with open ended questions were used. These methods were employed in evaluating COBES field attachment of third year medical students who were sent to different districts hospitals in the country but attached to rural primary health care facilities.

\section{Study setting}

The students' perceptions were collected through semi-structured questionnaires at the end of the rotation.

The study was conducted at the primary health care facilities which were either independent unit or attached to district hospital.

\section{Evaluation of forms}

All students were asked to respond to a semi-structured questionnaires after finishing their rural community health attachment. Then a random sample of those filled forms were selected from each cohort of students in the year 2013,2014 and 2015 .

\section{Research Ethics}

Students had option to fill in those forms as they were not part of students' evaluation. All those who did not fill in those form were not penalized

\section{Data analysis}

There were multiple responses about the importance of each objective presented to them. They could either report that they were very important or less important as seen in the table below.

\section{RESULTS}

A total of 100 students were analyzed 30 out $55(55 \%)$ in the year 2013,35 out of $65(54 \%)$ in 2014 and 35 out of $68(51 \%)$ in 2015 .

Table. 1 Relative importance of field attachment objectives as reported by students

\begin{tabular}{|c|c|c|c|}
\hline Objective & $\begin{array}{l}\text { Very } \\
\text { important. } \\
(\%)\end{array}$ & $\begin{array}{l}\text { Somehow } \\
\text { important } \\
(\%)\end{array}$ & $\begin{array}{l}\text { Less } \\
\text { important } \\
(\%)\end{array}$ \\
\hline $\begin{array}{l}\text { To study the structure, staffing, functions and problems of health care } \\
\text { delivery in rural settings in relation to the national guidelines and } \\
\text { health care policy in Namibia }\end{array}$ & 53 & 41 & 6 \\
\hline $\begin{array}{l}\text { To understand the practical elements of primary health care } \\
\text { management including patients flow, triage medical records keeping, } \\
\text { patients confidentiality, day to day health care servicing and } \\
\text { coordination of all day to day activities the primary health care settings }\end{array}$ & 68 & 18 & 16 \\
\hline $\begin{array}{l}\text { Appreciate working with multidisciplinary team including nurses, } \\
\text { health officers, attendants, village leaders and political figures. }\end{array}$ & 65 & 32 & 3 \\
\hline $\begin{array}{l}\text { Improving efficiency and practical skills in conducting a direct history } \\
\text { taking, physical examination and performing outpatient procedures } \\
\text { under guidance of experience primary health care staff. }\end{array}$ & 100 & 0 & 0 \\
\hline $\begin{array}{l}\text { Identify major health problems in the community and thus gave health } \\
\text { education sessions }\end{array}$ & 90 & 10 & 0 \\
\hline $\begin{array}{l}\text { To appreciate the challenges involved in providing healthcare to } \\
\text { medically underserved and impoverished population }\end{array}$ & 34 & 48 & 18 \\
\hline To appreciate the relationship between poverty and diseases & 49 & 45 & 6 \\
\hline
\end{tabular}

Among the studied students $68 \%$ were females. The male female ratio of students at the school of medicine is about 1:3. So that ratio coincides with the male: female ratio in the School of Medicine. Some of the students were born and raised in towns and cities environment, so they had never been exposed to rural life styles

All students (100\%) regardless of health facility they were allocated acknowledged improvement in their efficiency and practical skills in conducting history taking, physical examination and performing outpatient procedures as outlined in the log-book under the guidance of experienced of staff members in the clinics. About 2/3 of all students appreciated the opportunity they were given to work in a multidisciplinary team of different cadres in the health care facilities. They also 
had the opportunity to interact with village leaders especially when they were doing community diagnosis exercise. Some students had the chance to interact with counsellors who are regarded as political leaders.

About $90 \%$ of all students studied acknowledged that communicating health issues when giving health education and /or health promotion messages to all those attending the primary health care facilities were very helpful in understanding the community they were serving except for the language barrier faced by some of the students. They learned how medical records are kept, how patients' confidentiality were handled, especially for those who come for medical treatment for diseases which are always stigmatized like HIV/AIDS, Sexually Transmitted Infections (STI) and Tuberculosis.

Apart from responding to the open-ended questions on the objectives students were required to write report on the COBES program. More than 2/3 of the students appreciated how the primary health care facilities were organized and coordinated on day-to-day basis. Unfortunately, less than $50 \%$ of the students analysed the association between poverty and diseases, also less than $55 \%$ of the students spent time to study the structure, staffing, functions and problems of health care delivery in rural settings in comparison with the national guidelines. This was mostly due to the fact that the national guidelines were not well known to most of our students. Apart from what they learned in the classroom settings we were expecting national guidelines to readily available in each health facility so that the students could use they in the evaluation exercise, unfortunately this was not the case

Students of the first cohort (2013) in the field attachment said that they were very much concerned about what lay ahead, given the absence of preceding peers to consult. Most of them were delighted or grateful as they received friendly welcome in those rural health care facilities. Other cohorts of 2014 and 2015 real enjoyed the attachments in general. The challenges faced in all three cohorts are presented elsewhere.

Students talk positively of having to adapt approaches and practices to different settings especially the importance of team work approach when attending to community members who visit the clinic for different reasons and when attending to patients. They also appreciated the ready accessibility of experienced primary health care staff and recognized the closeness of the learning experience to subsequent practice.

Almost all the students enjoyed the rural community attachment, reported broader range of practical skills learnt, kind patients and health staff members, friendly and polite supervisors by the primary health care staff. These factors were deemed as positive factors in a rural working life. The majority of students felt their relationship with the rural primary health care supervisors was better than with their urban and university supervisors for the following reasons:

\section{Comments from three students}

*" Working in the rural primary health care setting was great; however life was too quiet and isolated, weekends were quite boring".

**"Thank you for organizing excellent field attachments. On my side it was a great learning experience. Participating in day to day activities in the primary health care facilities was great; however, we didn't have anything to do in those small district towns during the weekends."

** Rural field attachment was a real an eye opener. It was an excellent learning environment without pressure and seeing cases which were not common at the teaching hospital. It was the best place to learn basic practical skills. It gave me the greatest field attachment experience I could have hoped for. It has definitely put perspective to my role as a medical doctor and to my future employment plans."

\section{DISCUSSION}

Community-based education and service is an approach that aims to prepare students for future professional work at the community level $(1,3,5)$. COBES instructional quality should be measured based on a program's outcomes. However, the association between learning objectives and attitude of students towards COBES is currently unknown.

All the three cohorts expressed that the rural replacement enhanced their learning and increased skills because they were exposed to a variety of medical problems hardly seen at the teaching hospital.

They did not need to wake up very early in the morning as it was a short commute time to and from work as transport was readily available and staying less than 10 kilometers from where they were residing. Had a more relaxed atmosphere with less pressures from supervisors as it happens in the teaching hospital.

In all cases accommodation for our students was at a nearby town usually within 10 kilometers from the health facility. In these places tap water and electricity were readily available and security for our students was assured.

They had more time to interact with patients attending the primary health care facilities and staff members compared to the teaching hospitals. Thus, they built stronger relationships, leading to a greater level of trust between staff and students. For the one month they were attached to the health facility there were no changeover of primary health care staff in all COBES identified sites, whereas the university teaching hospital and primary health facilities in urban areas used a large number of different supervisors, which reduced time to spend with students.

COBES students while on field attachment participate on sensitising nearby secondary schools students on various healthrelated issues including sexually transmitted infections (including HIV), adverse effects of illicit drugs, oral hygiene, personal hygiene, advantages of male circumcision, adverse effects of premarital sex and other health related topics relevant to the locality of the School and the health facility.

Students gained an understanding of the difficulties in recruiting and retaining of well-trained primary health care workers in these types of settings. 
Challenges were also noted in these rural settings, equipment and medical technicians were always lacking and doctors used to visit those settings sometimes twice a week and, in some areas, once a week.

As expected, some of the students complained that rural life was too quiet and isolated. They were missing friends, relatives and partners.

Some of the students sympathized with rural community people regarding the quality of health care services they were receiving and were willing to come back to rural areas to practices medicine after graduation. Another issue noted is that those born and raised it town or cities really enjoyed the rural attachment, this was an eye opener to the real life in the rural settings

The primary health care facility supervisors proved exemplary during the COBES attachments and their commitment was essential to the program's success. This supports the studies from James Cook and Melbourne Universities, who reported that the quality of supervisors is an integral aspect of a successful placement program $(9,12)$. The rural supervisors were more likely to spend more time with the students compared with teaching hospital staff, and students felt more at ease. Strong personal relationships were more likely to be built between student and rural supervisor especially when they were not very busy with patients

Almost all the students enjoyed the rural community setting and aspects noted were: 'being treated with kindness and respect from the patients and staff', they had sufficient time to observe, learn and practices some skills spelt out in their $\log$ books. Most of the students were staying in nearby towns and the working environments had more relaxed atmosphere and a broader range of clinical and health related problems.

Many of the challenges reported by the students relate to lack of technical and specialist support. Inadequate number of staff members in the primary health settings was reported in almost all health facilities where students were attached. This had negative effects on students as the staff members were sometimes concentrating more on taking care of patients.

Unfortunately, not all objectives of the program were addressed sufficiently by the students. Students concentrated on acquiring practical skills including history taking and physical examinations. All students were able to see how the primary health care setting works in the country and the challenges faced. Graduating doctors will be part of health care system in the country so they need to know how it works.

Undergraduate degree programs for medical students need to be designed, delivered and evaluated primarily with the understanding that they are preparing students to give services to both urban and rural communities. Because medical training in Namibia is done in urban areas there is need to pay special attention to students to make sure that they are exposed to rural primary health care facilities that engage in rural community health practice.

Undergraduate programs in public health should be carefully and regularly benchmarked against the needs of the community and local employers. This necessitates regular collection and analysis of data from alumni, preceptors, communities and employers, as well as periodic re-evaluation of future trends and directions in the needs and expectations of the communities and employers. We require each of our programs to undergo such a review every 4 years. An additional source of useful data can be collected from students when they return from their field attachment $(1,12)$.

\section{Acknowledgement}

Community based Education and services (COBES) field attachments would not have been possible without the financial support from The University of Namibia. We thank the founding Dean School of Medicine and his team for his support. We thank The Ministry of Health and Social Services for allowing our students to use their facilities for training. Special thanks to district hospitals and primary health care staff for training and guiding our students. Without such support this study would not have been completed

\section{References}

[1].Masanobu Okayama, Eiji Kajii . Does community-based education increase students' motivation to practice community health care? - A cross sectional study. BMC Med Educ. 2011; 11: 19.

[2].World Health Organization. Increasing access to health workers in remote and rural areas through improved retention global policy recommendations. World Health Organization. Geneva: World Health Organization, 2010:1-80. [PubMed]

[3].Huntington I, Shrestha S, Reich NG et al. Career intentions of medical students in the setting of Nepal's rapidly expanding private medical education system. Health Policy Plan 2012; 27:417-28. doi:10.1093/heapol/czr052 [PubMed]

[4].Ahmed SM, Majumdar MAA, Karim R et al. Career choices among medical students in Bangladesh. Adv Med Educ Pract 2011; 2:51-8. doi:10.2147/AMEP.S13451 [PMC free article] [PubMed]

[5].Burch VC, McKinley D, van Wyk J et al. Career intentions of medical students trained in six sub-Saharan African countries. Educ Health 2011;24:614. [PubMed]

[6].Mbalinda SN, Plover CM, Burnham G, Kaye D, Mwanika A, Oria H, Okullo I, Muhwezi W, Groves S. Assessing community perspectives of the community based education and service model at Makerere University, Uganda: a qualitative evaluation. BMC Int Health Hum Rights. 2011;11 Suppl 1:S6.

[7].Kiguli S, Mubuuke R, Baingana R, Kijjambu S, Maling S, Waako P, Obua C, Ovuga E, Kaawa-Mafigiri D, Nshaho $\mathrm{J}$, et al. A consortium approach to competency-based undergraduate medical education in Uganda: process, opportunities and challenges. Educ Health (Abingdon). 2014; 27(2):163-9. 
[8].Simpson SA; Long JA. Medical student-run health clinics: important contributors to patient care and medical education. J Gen Intern Med. 2007; 22(3):352-6

[9].Daniel Kabonge Kaye; Wilson Winstons Muhwezi;, Ann N Kasozi;, Steven Kijjambu;,

[10]. Scovia Nalugo Mbalinda;, Isaac Okullo;, Rose Chalo Nabirye;, Hussein Oria;, Lynn Muhimbuura Atuyambe; Sarah J. Groves; Gilbert Burnham;, Andrew Mwanika. Lessons learnt from comprehensive evaluation of communitybased education in Uganda: a proposal for an ideal model community-based education for health professional training institutions. BMC Medical Education 2011 11:7 (Bio Med Central blog)

[11]. Talib ZM, Baingana RK, Sagay AS, Van Schalkwyk SC, Mehtsun S, Kiguli-Malwadde E. Investing in community-based education to improve the quality, quantity, and retention of physicians in three African countries. Educ Health (Abingdon). 2013;26(2):109-14.

[12]. Samuel Kizito, Rhona Baingana, Kintu Mugagga, Peter Akera, and Nelson K. Sewankambo

[13]. Influence of community-based education on undergraduate health professions students' decision to work in underserved areas in Uganda.

[14]. BMC Res Notes. 2017; 10: 726.

[15]. Randy Wykoff; Amal Khoury;, J. Michael Stoots;,Robert Pack. Undergraduate Training in Public Health Should Prepare Graduates for the Workforce. Front Public Health. 2014; 2: 285. 